\title{
MIDAS
}

Museus e estudos interdisciplinares

Dossier temático: "Políticas culturais e museus"

\section{Robert R. Janes e Richard Sandell, eds. - Museum Activism}

Laura Castro

\section{OpenEdition}

1 Journals

\section{Edição electrónica}

URL: https://journals.openedition.org/midas/2852

DOI: $10.4000 /$ midas. 2852

ISSN: 2182-9543

\section{Editora:}

Alice Semedo, Paulo Simões Rodrigues, Pedro Casaleiro, Raquel Henriques da Silva, Ana Carvalho

\section{Refêrencia eletrónica}

Laura Castro, «Robert R. Janes e Richard Sandell, eds. - Museum Activism», MIDAS [Online], 13|2021, posto online no dia 15 dezembro 2021, consultado no dia 06 março 2022. URL: http:// journals.openedition.org/midas/2852 ; DOI: https://doi.org/10.4000/midas.2852

Este documento foi criado de forma automática no dia 6 março 2022

\section{(c) (i) (2)(2)}

Midas is licensed under a Creative Commons Attribution-NonCommercial-ShareAlike 3.0 International License 


\title{
Robert R. Janes e Richard Sandell, eds. - Museum Activism
}

\author{
Laura Castro
}

\section{REFERÊNCIA}

Janes, Robert R., Richard Sandell, eds. 2019. Museum Activism. London: Routledge. 405 páginas, ISBN: 978-0-815-36996-7.

Publicado na prestigiada série Museum Meanings, sucessivamente dirigida por alguns dos autores e dos pensadores mais destacados no campo da museologia internacional que, desde os finais da década de 90 do século passado e, particularmente, desde o início do século XXI, tem apresentado perspetivas críticas, fraturantes e inclusivas acerca de temas de museologia contemporânea, Museum Activism é um volume coordenado por Richard Sandell e Robert R. Janes.

O primeiro é um dos diretores da série, onde já publicou Museums, Moralities and Human Rights (2016), coeditou Museums, Equality and Social Justice (2012) e editou Museums, Society, Inequality (2002), tendo coeditado, fora desta série, Re-Presenting Disability: Activism and Agency in the Museum (2010); o segundo é autor de Museums in a Troubled World: Renewal, Irrelevance or Collapse? (2009), títulos que refiro por traduzirem, de forma expressiva, os interesses dos autores e complementarem a abordagem que o presente livro propõe. Richard Sandell dirige o Research Centre for Museums and Galleries da Universidade de Leicester e Robert R. Janes é editor emérito da revista Museum Management and Curatorship. Ambos advogam a relevância social dos museus, aspeto que perpassa as respetivas carreiras e obras, marcadas, não apenas pela investigação, mas por uma prática empenhada e comprometida com a causa social.

3 Museum Activism é um extenso volume com 34 capítulos de 53 autores, cuja afiliação atesta a diversidade e a representatividade que a publicação pretende afirmar. Os nomes são oriundos do campo universitário e da investigação, da consultadoria, do meio cultural e associativo independente, do contexto dos profissionais de museus - de 
diversa natureza e estatuto - surgindo, igualmente, artistas, curadores e educadores. Se alguns capítulos focam casos específicos localizados numa matriz geográfica e cultural globais, cobrindo, a título de exemplo, Colômbia, Zimbabwe, Canadá, China, Brasil, Estados Unidos da América, Reino Unido, Iraque, Noruega ou Austrália, outros optam por abordagens temáticas transversais.

O livro organiza-se em três partes: "Nurturing Activism», "Activism in Practice» e «Assessing Activism», e contempla o que podemos considerar como o ciclo ativista, desde as ideias e as ações de sensibilização, os primeiros passos para o enraizamento de uma mentalidade ativista, passando pelas práticas e casos já implementados, até à avaliação dos resultados e dos impactos, e à correspondente reflexão.

Os temas são, entre outros, os expectáveis: migrações e refugiados, colonização e descolonização; feminismo; ambiente e biodiversidade; acessibilidade e deficiência; justiça, intolerância e direitos humanos. Este elenco tem por base dois pressupostos: o primeiro pressuposto assenta na necessidade de mudar os museus para, por sua vez, mudar o mundo. Esta é uma perspetiva curiosa que se reflete em alguns capítulos sobre o universo interno dos museus, tais como o que aborda o papel ativista dos profissionais de museu, a sua consciencialização e responsabilidade (de Victoria Hollows) ou as assimetrias de poder nestas instituições, expressas nos discursos veiculados e nas exposições organizadas, bem como nos fenómenos de autocensura (de Kevin Coffee). O segundo pressuposto assenta na necessidade de os museus se mobilizarem e operarem com base em princípios éticos. Embora a palavra ética não faça parte do título, ela está presente no prefácio ao assinalar o "pensamento socialmente empenhado e eticamente informado» (p. xxvii) que norteia a publicação. E a ética também está disseminada pelos vários temas, sendo referência concreta no tópico que a confronta com o patrocínio e o mecenato dos museus. Aqui reside uma das questões críticas que nos são propostas, a dos riscos que os museus enfrentam ao suportar causas que visam diretamente os seus esteios financeiros, com um dos capítulos a abordar os patrocínios das petrolíferas no Reino Unido (de Paula Serafini e Chris Garrard). Os limites entre a ética e a moral também estão presentes, nomeadamente no capítulo sobre museus e emergência climática (de Steve Lyons e Kai Bosworth) que questiona o conceito de "propaganda moral" e no texto que questiona o impacto dos museus do Holocausto e a ritualização moralizadora da memória (de Diana I. Popescu).

6 Museum Activism dá-nos a conhecer o que está a ser feito no presente. A transversalidade, quando não o desencontro temático, é fundamental na dinâmica ativista, desafiando a especialização tipológica, difícil de definir e balizar em numerosas situações, e levando os museus a abraçar temas aparentemente inapropriados. Os casos selecionados evidenciam, igualmente, a panóplia de possibilidades em que a prática ativista pode ser incluída: a organização de exposições e performances artísticas, a contratação de consultadoria e auditoria para a inclusão, a criação de plataformas digitais e a formação de grupos de discussão ou até a própria estratégia de criação de museus e coleções como ocorreu, respetivamente, com o Museu Nacional da Memória, na Colômbia, e com o Hong Kong Umbrella Movement. Nem todos os casos são analisados num tom positivo, inquirindo também fenómenos de rejeição e de receção controversa de exposições, vistas como zonas de contacto/conflito, como o estudo sobre Into the Heart of Africa e of Africa, do Royal Ontario Museum, no Canadá (de Silvia Forni, Julie Crooks e Dominique Fontaine). 
7 Habituámo-nos, pelo menos nas últimas décadas, a este discurso sobre os museus que parece ignorar as suas coleções e os seus objetos. Na verdade, não se trata de ignorar esta importante dimensão institucional que são as coleções, trata-se antes de trabalhar, não sobre elas, mas a partir delas e de encarar os museus, não como repositórios de objetos, mas como repositórios de problemáticas que urge debater também no seu interior. Produzir discurso e ocupar posição na esfera pública a partir de corresponde a escolher assuntos que podem não estar inscritos na primeira missão dos museus, mas que corporizam o seu destino último que é funcionarem para a sociedade e não para os objetos. Faz-se certamente museologia de fora para dentro e não de dentro para fora, em total afinidade com o que, na área da conservação do património e na sua Teoría Contemporánea de la Restauración (2004), Salvador Muñoz Viñas defende: uma conservação para a sociedade e não para os objetos. Nada de novo e, ainda assim, completamente novo.

8 Ao percorrer o website do Conselho Internacional dos Museus (ICOM), a organização não governamental responsável pelas linhas orientadoras da museologia, pela recomendação de boas práticas e pelos padrões éticos da atividade dos museus, quais são os temas dominantes? De que fala o ICOM por estes tempos? Discute como reverter a recente experiência de reclusão através dos meios digitais; como envolver comunidades, ouvir histórias e cultivar a memória; apela ao papel social dos museus; debate igualdade, mobilização, inclusão e reconciliação; perspetiva a sustentabilidade. Os objetivos do último plano estratégico do ICOM (2016-2022) propõem, no mesmo sentido, que a organização promova internamente práticas de participação e empenho dos seus membros, tal como os museus são desafiados a promover processos de participação e valorização das comunidades. No website do Conselho Internacional de Monumentos e Sítios (ICOMOS), a organização não governamental dedicada à preservação dos lugares patrimoniais, de natureza muito diversa, quais são os temas dominantes? De que fala o ICOMOS por estes tempos? De conflitos, guerras, catástrofes; de património difícil, em risco e em negociação; de direitos humanos, refugiados e migrações; de memória e identidade; de sustentabilidade e mudança climática; de digitalização. No ICOM e no ICOMOS Portugal os tópicos noticiados não se afastam destes.

9 E, no entanto... se percorrermos os websites dos museus nacionais a perceção é a de que o trabalho dominante se faz, ainda sobre as coleções e os objetos e que, apenas pontualmente, se testemunham iniciativas a partir desses ativos. Exemplos como os que este livro oferece podem estimular novas ações que colocam a responsabilidade cívica no coração dos museus e reconhecer que a dinamização do que possuem ganha em ser feita a partir da pressão do presente.

\section{BIBLIOGRAFIA}

ICOM. 2016. Strategic Plan 2016-2022. ICOM (International Council of Museums). 
Janes, Robert. 2009. Museums in a Troubled World: Renewal, Irrelevance or Collapse? London: Routledge.

Muñoz Viñas, Salvador. 2004. Teoría Contemporánea de la Restauración. Madid: Editorial Síntesis.

Sandell, Richard, e Eithne Nightingale. 2012. Museums, Equality and Social Justice. Oxon: Routledge.

Sandell, Richard, Jocelyn Dodd, e Rosemarie Garland-Thompson, eds. 2010. Re-Presenting Disability: Activism and Agency in the Museum. New York: Routledge.

Sandell, Richard. 2002. Museums, Society, Inequality. London: Routledge.

Sandell, Richard. 2016. Museums, Moralities and Human Rights. Oxon: Routledge.

\section{AUTORES}

\section{LAURA CASTRO}

Universidade Católica Portuguesa, Escola das Artes - Centro de Investigação em Ciência e Tecnologia das Artes, Portugal, lcastro@porto.ucp.pt 